\title{
Perforant Path Damage Results in Progressive Neuronal Death and Somal Atrophy in Layer II of Entorhinal Cortex and Functional Impairment with Increasing Postdamage Age
}

\author{
Daniel A. Peterson, Carrie A. Lucidi-Phillipi, Kaaren L. Eagle, and Fred H. Gage \\ Department of Neurosciences, University of California at San Diego, La Jolla, California 92093-0627
}

In vivo model systems that can evaluate neuronal death, survival, and regeneration are critical to revealing basic mechanisms of neuronal response and developing strategies for CNS repair. We propose a distinct experimental model of CNS degeneration following lesions to the perforant path connecting the hippocampus and the entorhinal cortex. Within 2 weeks of a unilateral aspirative perforant path lesion, $30 \%$ of the ipsilateral entorhinal cortex layer II (ECL II) projection neurons had died with no change in the contralateral ECL II population. Although there was no loss of ECL II neurons with normal aging, animals that survived for 15 months postlesion experienced an almost $50 \%$ loss of ipsilateral neurons compared to unlesioned controls. This progressive neuronal death was bilateral, with the contralateral ECL II experiencing a $30 \%$ decline in neuronal number relative to unlesioned controls. The use of unbiased stereology ensured that estimates of total number were not distorted by changes in the reference volume. The documented progressive neuronal death resulted in delayed behavioral impairment in spatial learning and performance (latency nearly $\mathbf{2 0 0 \%}$ of controls). We propose, therefore, that the perforant path model is suitable for experimental investigation of neuronal survival and regeneration following CNS trauma.

[Key words: cell death, lesion, degeneration, stereology, cell volume, confocal microscopy, water maze, Fast Dil]

While many tissues respond to trauma by mitotic replacement of lost cell populations and reestablishment of histotypic architecture, the CNS has a limited regenerative capacity. Lesions that directly harm neuronal cell bodies or axotomize processes too close to the neuronal soma result in chromatolytic changes that frequently lead to neuronal death. Even with neuronal survival, contact with the natural target region is seldom reestablished through regenerative outgrowth.

The effect of axotomizing lesions on survival and regeneration of projection neurons has been extensively studied using the fimbria-fornix lesion model. Fimbria-fornix lesions axotomize cholinergic and GABAergic septal neurons that project to the dorsal hippocampus. Up to $60 \%$ of the cholinergic neurons with-

Dec. 20, 1993; revised May 13, 1994; accepted May 16, 1994.

We thank Mr. Steve Forbes and Mr. Chung Ho for technical assistance. This research was supported by NIH Grants PO1-NS-28121, PO1-AG-10435, and RO1-AG-06088. D.A.P. was supported by NIA Fellowship AGO5512.

Correspondence should be addressed to Dr. Fred H. Gage, Department of Neurosciences, 0627, University of California at San Diego, La Jolla, CA 920930627.

Copyright (C) 1994 Society for Neuroscience $0270-6474 / 94 / 146872-14 \$ 05.00 / 0$ in the medial septum die, with cell loss seen as early as 2 weeks following fimbria-fornix lesion (Gage et al., 1986). Cell death is reduced when exogenous trophic factors, including NGF and brain-derived neurotrophic factor (BDNF), are delivered into the ventricle or septal parenchyma. Grafts of somatic cells genetically engineered to produce these trophic factors also have lead to a reduction in cell death (Hefti, 1986; Williams et al., 1986; Kromer, 1987; Gage et al., 1988; Rosenberg et al., 1988; Stromberg et al., 1990; Lucidi-Phillipi et al., 1992; Morse et al., 1993). The fimbria-fornix model has been extended to demonstrate histotypic reinnervation across grafts of fetal tissue (Tuszynski et al., 1990), peripheral nerve homogenate (Wendt, 1985), human amnion (Davis et al., 1987), and genetically engineered cells (Kawaja et al., 1992) that can lead to functional restoration (Eagle et al., 1992).

While neuronal rescue and recovery have been demonstrated by these studies, the cholinergic system, the medial septum in particular, maintains a diffuse projection system to many regions of the CNS. The observed regenerative responses may be due to the lack of specificity within the cholinergic system and such phenomena might not be generalized to other neuronal populations. In addition, the inability to specify which population of cholinergic septal cells projects exclusively to the hippocampus through the fimbria fornix has complicated the assessment of neuronal survival following fimbria-fornix lesion.

To determine the generality of trophic factor efficacy on projection neuron rescue and regenerative capacity, we propose an analogous but phenotypically distinct model to the fimbria-fornix lesion using lesions of the perforant path fibers connecting the hippocampus with the entorhinal cortex. This perforant path model differs from the fimbria fornix model in several important respects, one of which is the precision of anatomical localization within the projection tissue. In contrast to the uncertain distribution of neurons in the medial septum, the neurons of the entorhinal cortex are organized in discrete laminae (Lorente de Nó, 1933; Finch et al., 1986; Köhler, 1986a,b, 1988; Witter et al., 1989; Germroth et al., 1991; Lingenhöhl and Finch, 1991). Layer II is characterized by a population of stellate cells, which together with layer III neurons, forms the entorhinal projection to the hippocampus via the perforant path (Steward and Scoville, 1976). The discrete location of the entorhinal projection neurons permits a greater specificity of lesion effect on projections neurons than is possible in the fimbria fornix model. Furthermore, within this laminar organization, entorhinal projections to the hippocampus follow a defined spatial distribution along the septotemporal axis of the hippocampus (Steward, 1976a; Wyss, 1981; Ruth et al., 1982, 1988). However, in a 
similar fashion to septohippocampal circuitry, the interconnections between the entorhinal cortex and the hippocampus have important functional implications in the processing of learning and memory (Squire and Zola-Morgan, 1991; Jones, 1993).

As a first step in developing a perforant path model of CNS regeneration, we determined the baseline of entorhinal cortex layer II (ECL II) neuronal loss and functional impairment following an aspirative partial lesion to the perforant path. Unbiased stereological procedures were used for quantitative assessment to ensure reliability in the estimates without distortion due to changes in the reference volume. Layer II was selected for quantitative study based upon its clear anatomical delincation and the well-defined course and termination of its projections within the perforant pathway. In this initial study, layer II neurons were identified only by position and morphology (Peterson et al., 1993); future studies will address the identification of specific phenotypic subpopulations.

\section{Materials and Methods}

Surgical and histological procedures. Female Fischer 344 rats were anesthetized with a mixture of ketamine $(75 \mathrm{mg} / \mathrm{kg})$, xylazine $(4 \mathrm{mg} / \mathrm{kg})$, and acepromazine $(5.6 \mathrm{mg} / \mathrm{kg}$ ) and placed in a Kopf stereotaxic frame where they received a right unilateral perforant path lesion, as previously described (Gage et al., 1988b; Fagan and Gage, 1990). Briefly, the skull was drilled to the right of lambda, the underlying dura removed, and the cortex aspirated. Retrohippocampal tissue corresponding to the presubiculum and angular bundle was aspirated under visual control using the hippocampus and splenium of the corpus callosum as landmarks until the vascular bed overlying the corpora quadragemina was visible (see Fig. $1 A-D$ ). The lesion cavity was packed with hydrated Gelfoam (Upjohn).

At 2 weeks $(N=3), 8$ weeks $(N=6)$, and at 15 months $(N=3)$ postlesion, animals were killed humanely under deep anesthesia by transcardial perfusion with a fixative mixture of $4 \%$ paraformaldehyde and $0.1 \%$ glutaraldehyde in $100 \mathrm{~mm}$ phosphate buffer. Unlesioned controls $(N-6)$ and a control group age-matched to the 15 month lesioned animals $(N=3)$ were also killed humanely. Brains were postfixed overnight in fixative, equilibrated in $30 \%$ sucrose, and horizontal sections $(50 \mu \mathrm{m})$ were cut on a freezing sliding microtome and stored in cryoprotectant (glycerol/ethylene glycol/phosphate buffer) at $-20^{\circ} \mathrm{C}$. A onein-six series of tissue sections was mounted on gelatin-coated slides and stained for Nissl substance using $0.5 \%$ aqueous thionine. The sample size above reflects animals that received accurate lesion placement determined by histological examination.

In a separate group of animals $(N=4)$, the Gelfoam was soaked in the lipophilic dye Fast DiI (Molecular Probes, Eugene, OR) before placement in the lesion cavity. DiI is taken up by intact and damaged membranes at the site of contact and diffuses both anterogradely and retrogradely (Honig and Hume, 1989). In this fashion, entorhinal neurons projecting through the site of lesion were retrogradely labeled and their distribution within the entorhinal cortex was noted (Fig. $1 E-H)$. After $5 \mathrm{~d}$, DiI-labeled animals were killed humanely and horizontal $(50 \mu \mathrm{m})$ vibratome sections were produced. The addition of a small percentage of glutaraldehyde to the fixative solution kept the DiI from spreading when the membranes were fractured by freezing, making the use of a freezing sliding microtome possible.

Bright-field microscopic observation, photography, and stereology were accomplished using an Olympus Vanox AH2 microscope equipped with video output (Hitachi) to a high resolution monitor (Sony). Photographic films were mastered onto Kodak PhotoCD and composite figures were assembled using Adobe PHOTOSHOP 2.51 running on a Macintosh Quadra 700. Final output of completed figures was made using a GCC Colorfast Film recorder or a Kodak XL7700 printer. Fluorescent observations of DiI labeling were made using an Olympus BHS microscope equipped with a rhodamine (BP 480-550 nm) filter set.

Determination of anatomical boundaries for quantitative stereology. Since the lesions to the perforant path were partial, axotomizing only those entorhinal neurons projecting to the dorsal hippocampus, it was necessary to set the boundaries for quantitation to include that population of projection neurons. As progressively more ventral horizontal sections were examined, the first encounter with an organized ECL II (Fig. 2), and with DiI labeling (Fig. 1E), always coincided with transection of the dorsal striatum in the same section (Fig. 1C,E). This feature set the dorsal boundary for quantitation. The ventral boundary was determined by examining the ventral extent of DiI labeling from the lesion site. The most consistent anatomical landmark present in the horizontal sections where Dil labeling was last observed were the bed nuclei of stria terminalis (BNST, Fig. $1 H$ ). The presence of these nuclei, where the striatum and septum meet, set the ventral boundary for quantitation.

The medial border of ECL II is apparent where a distinct laminar organization of neurons emerges from the loosely organized parasubiculum (Fig. 2). The lateral extent of ECL II increases gradually on a dorsal to ventral gradient, so that in far ventral sections ECL II extends on the lateral surface of the cortex to the rhinal fissure. Examination of Dil labeling revealed that the population of neurons affected by the axotomizing lesion in more dorsal sections (Fig. $1 E$ ) were located from the medial border of ECL II lateral until the cortex began to make a curvature between posterior and lateral cortex. In the most ventral sections (Fig. $1 H$ ), Dil labeling began just lateral to the medial border and extended laterally around the curvature to the lateral cortex. Intervening sections (Fig. $1 F, G$ ) demonstrated a transition between the dorsal and ventral distribution.

It was not considered practical and reproducible to incrementally adjust the medial and lateral quantitative boundaries to correspond exactly to the distribution of DiI labeling between horizontal sections. Instead, discrete medial and lateral quantitative boundaries were set that would be used for each horizontal section between the dorsal and ventral boundaries. The medial boundary was set to be the anatomical medial boundary of layer II in each section (Fig. 2). The lateral boundary was set to be an imaginary line from the splenium of the corpus callosum to the apex of the cortical curvature between posterior and lateral cortices (Fig. 2). While these boundaries would result in sampling an unaffected population in the far medial aspect of the most ventral sections and fail to sample an affected population in the far lateral aspect of the most ventral sections, sampling would be conducted in a fashion that was inclusive for most of the sections within an animal and for reproducibility of sampling between animals.

Cavalieri estimator of reference volume. The volume of ECL II was determined using the method of Cavalieri (Michel and Cruz-Orive, 1988), as we have described previously (Peterson et al., 1992; Peterson and Jones, 1993). Briefly, a point counting grid printed on an acetate sheet was placed over the video monitor upon which the whole entorhinal cortex was displayed using a low power objective $(4 \times)$. The area around each point was calibrated using a stage micrometer. By knowing the distance $(d)$ between sections and multiplying that by the area per point $\left(A_{p}\right)$, each point served as a volume probe (analogous to a voxel in image processing). The total volume $\left(V_{\text {ref }}\right)$ of ECL II was determined by counting the number of points $(Q)$ overlying layer II in semiserial (one-in-six) sections and multiplying that sum $(\Sigma Q)$ by the volume associated with each point according to the formula $V_{\text {ref }}=(\Sigma Q)(d)\left(A_{p}\right)$.

Optical disector estimator of neuron number. The number of ECL II neurons in thionine-stained sections was determined using the unbiased optical disector method (Sterio, 1984), which we have described previously (Peterson et al., 1992). Briefly, a one-in-six series of horizontal sections was observed on an Olympus Vanox $\mathrm{AH} 2$ microscope using a high-numerical-aperture objective $(60 \times)$. An unbiased counting frame was printed onto an acetate sheet and placed on a high-resolution monitor screen from which the video signal from the microscope was displayed. Calibration of focusing depth (z-travel) was accomplished using an electronic microcator (Heidenhain model MT12).

Each section was positioned so that the counting frame overlaid the lateral quantitative border of ECL II. The precise counting frame position was determined by randomly selecting one of three contiguous frame areas beginning at the lateral quantitative border. The counting frame was applied to that region and every third contiguous region in a medial direction until the medial quantitative border was reached. The number of neurons in the frame was counted according to the rules for use of the optical disector (Sterio, 1984; Peterson et al., 1992). Briefly, the counting frame consists of a known area ( $\mathrm{x}$ - and $\mathrm{y}$-axes) that is easily calibrated using a stage micrometer. By focusing into the tissue a known distance (using the microcator), one can sample a known, miniature volume. The cells in this miniature volume that meet the selection rules are counted, yielding a number per known volume, or numerical density value $\left(N_{v}\right)$, which is averaged for the entire sampled region. Since the 

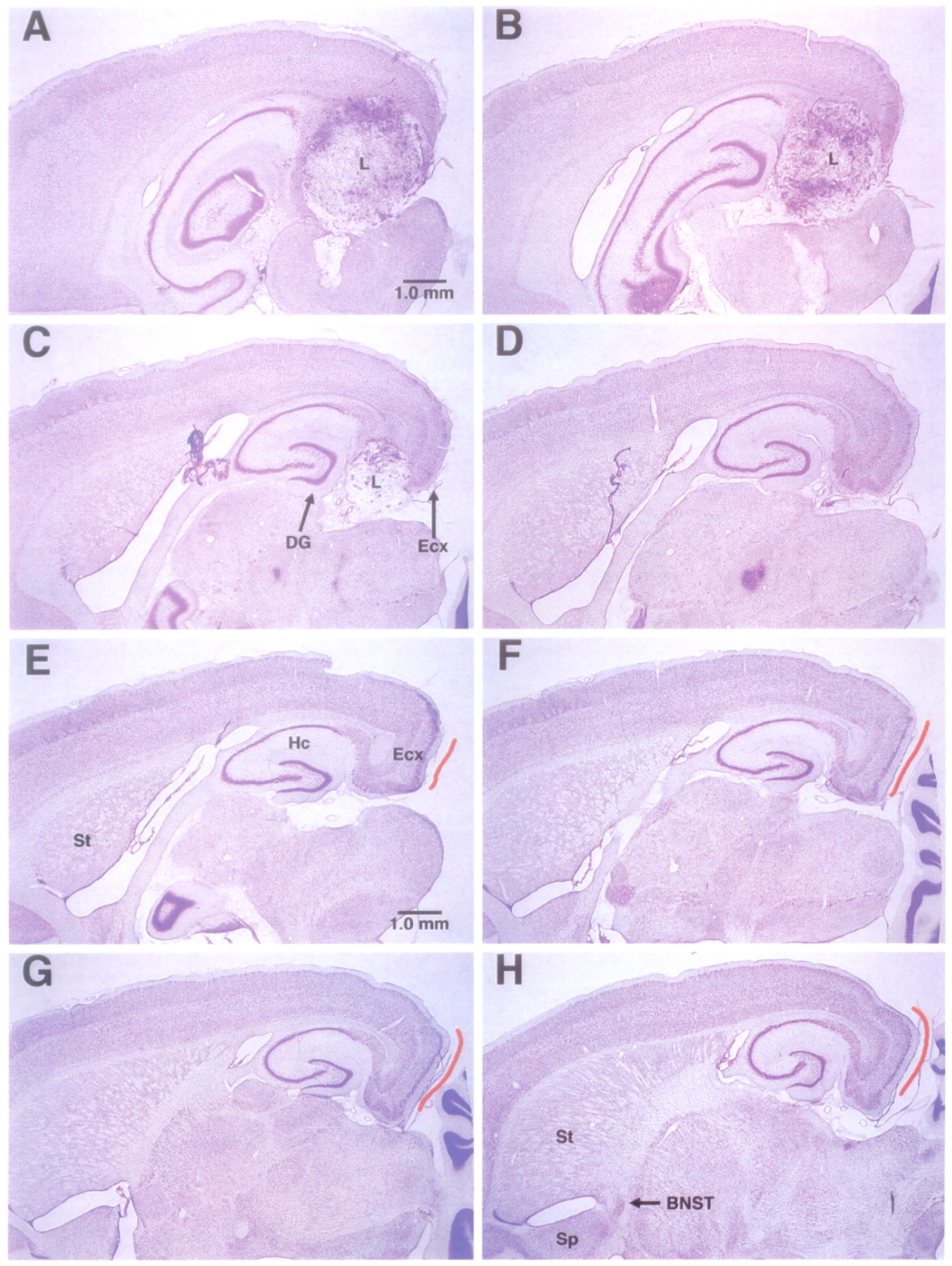


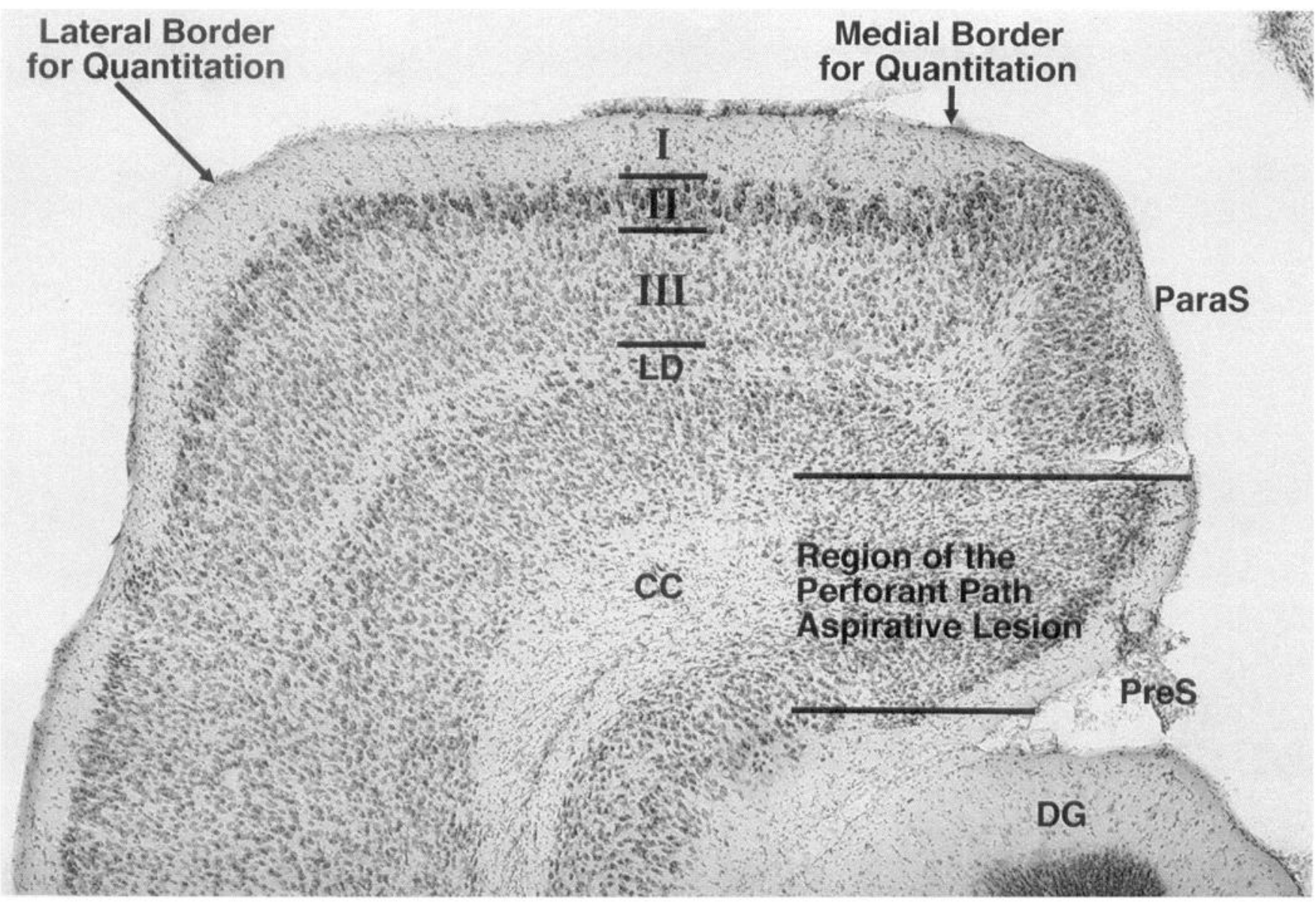

Figure 2. Horizontal section through the right entorhinal cortex of an unlesioned animal at a level corresponding to Figure $1 G$. Entorhinal cortex layer II is clearly visible between the relatively cell-free layer I and the less compact layer III, below which lies the lamina desicans $(L D)$. The medial boundary for quantitation of layer II began where layer II forms from the loosely organized parasubiculum (ParaS). The lateral border for quantitation was set for all dorsoventral levels where an imaginary line anchored in the splenium of the corpus callosum $(C C)$ intersected the apex of the lateral aspect of the entorhinal cortex. The region of the perforant path that was interrupted by the aspirative lesion in more dorsal sections is shown just caudal to the dentate gyrus $(D G)$ and corresponds to the area of the presubiculum (PreS).

actual reference volume of ECL II had been determined by the Cavalieri procedure, the total number of neurons in ECL II can be calculated by multiplying the mean number per known sample volume by the total volume of the region. This value is not a density measurement but an estimation of the total or absolute number $\left(N_{\mathrm{abs}}\right)$ of neurons present. This approach to quantitation is not biased by neuronal size, shape, or distribution, or by volumetric changes in the containing structure due to either experimental or artifactual effects (see Gundersen, 1986, for a review).

Estimation of neuronal volume. To determine the extent of somal shrinkage in ECL II neurons following perforant path axotomy, the volume of surviving neurons was estimated by unbiased stereology, as we have described previously (Peterson et al., 1993; see also Prakash et al., 1993, for similar methodology developed independently). Neu- rons were sampled in an unbiased fashion using the disector procedure as described above for estimation of neuron number. In this application, the volume of selected neurons was estimated by applying the Cavalieri procedure to successive optical sections as provided for in Formula 7 of the original report describing the disector (Sterio, 1984). In practice, a variation of the disector sampling called the selector procedure (CruzOrive, 1987; Peterson and Jones, 1993) was implemented.

Traditional bright-field microscopy of thionine-stained sections provided inadequate resolution to distinguish somal profile boundaries at successive serial optical sections due to the projection of unfocused images above and below the plane of focus. To circumvent this difficulty, the weak fluorescence of the thionine stain was imaged using confocal microscopy. A registered z-series of seven images at $1 \mu$ m intervals was imaged using a Bio-Rad MRC600 confocal microscope equipped with

Figure 1. $A-D$, Sequential horizontal thionine-stained sections through the right hemisphere of a perforant path-lesioned animal at $300 \mu \mathrm{m}$ intervals. The lesion cavity $(L)$ is filled with Gelfoam and separates the entorhinal cortex $(E c x)$ from the dentate gyrus $(D G)$ by axotomizing the perforant path. $D$ was the first section in which the lesion was no longer visible and indicates the ventral extent of the lesion. $E-H$, Sequential horizontal sections (600 $\mu \mathrm{m}$ intervals) through the right hemisphere from another lesioned animal that had received Fast Dil-soaked Gelfoam packed into the lesion cavity. The extent of entorhinal DiI labeling that was visible in adjacent sections using fluorescence microscopy is indicated by red lines traced upon these thionine-stained images to illustrate the anatomical boundaries. Entorhinal DiI labeling was first observed at the level where the dorsal portion of the striatum $(S t)$ began to be sectioned $(E)$. This level $(E)$ is also where an organized entorhinal cortex layer II was first visible, therefore quantitation of layer II began at this level ( $H c$, hippocampus; $E c x$, entorhinal cortex). As sections progressed ventrally $(F-H)$, the entorhinal DiI labeling extended laterally, including a portion of the lateral entorhinal cortex $(H)$. Entorhinal DiI labeling was last seen $(H)$ in sections passing through the bed nuclei of stria terminalis $(B N S T)$ located between the striatum $(S t)$ and septum $(S p)$; therefore, this level $(H)$ marked the ventral boundary for quantitation of layer II. 


a krypton-argon laser and coupled to an Olympus IMT-2 microscope. The $588 \mathrm{~nm}$ laser wavelength coupled with the YHS filter set (568DF 10 excitation/585EFLP emission) was found to be optimal for this material. Images were acquired in split screen mode so that transmitted field images were seen next to the confocal image at each focal plane; this permitted unambiguous identification of confocal profiles that were tangential to the soma and assured that all profiles were sampled. A $60 \times$ (1.4 NA) oil objective was used with an electronic zoom of $2 \times$. The optical depth of field at these settings was determined to be $0.43 \mu \mathrm{m}$; therefore, there was no overlap of images taken at $1 \mu \mathrm{m}$ intervals.

Once images were acquired, they were analyzed off line by scrolling forward and backward through the stack of optical sections for unbiased selcction and measurement. The weak fluorescence of the thionine resulted in poor emission and shadowing from optical planes deeper into the tissue. In practice, the fall-off of emission limited the useful penetration of the laser to less than $10 \mu \mathrm{m}$ in most cases. Since this depth was less than the probable diameter of the neurons to be imaged, it was possible to measure directly only neuronal half-volume. Briefly, neurons that appeared in section 3 of the optical stack, but not section 6 were selected for sampling (the selector procedure); section 7 served as a guard region to help further identify all profiles appearing in section 6 . Each neuron selected was assigned a unique identifying number, and its profile was measured by the Cavalieri procedure in sections $1-5$. Once the maximal profile size was attained, no further measurements were made and the mean neuronal half-volume was calculated from the raw data. Approximately 40 neurons were measured from each animal in cach group. The half-volume was doubled for presentation of the final data as full somal volume of surviving ECL II neurons. It should be noted that this was a post hoc application on material prepared for normal bright-field microscopy. It should be possible to amend preparation techniques to allow enhanced imaging and direct measurement of the full somal volume.

Behavioral testing. Perforant path-lesioned and unlesioned control rats were tested for spatial learning and memory using the Morris water maze (Morris, 1984). Rats were placed in a 6 foot diameter circular pool of water containing an escape platform in one of its four quadrants. Each rat was tested for a maximum of $90 \mathrm{sec}$ per trial, with $10 \mathrm{sec}$ rest between each trial. Testing consisted of four trials per day, each trial starting from a different quadrant of the pool. Rats were tracked with a video tracking system (San Diego Instruments, San Diego, CA) that recorded the path of the rat, the distance swam in each trial, and the latency to find the platform. The beginning and end of each trial were signaled by the operator using a pneumatic switch.

At 8 weeks postlesion, the physical capability of rats to swim and to climb onto the platform was tested for $5 \mathrm{~d}$, during which the platform had a visible white top and was located in different quadrants every day. This test was followed by ten days of testing with the platform hidden $1 \mathrm{~cm}$ below the surface and located in the SW quadrant of the pool. Testing was repeated 4,6, and 14 months after surgery. At the 14 month time point rats received one day of visible platform testing to ensure that aging had not impaired their ability to swim and climb onto the platform. They were then tested for $10 \mathrm{~d}$ with the platform hidden in the SW quadrant, just as at 8 weeks. Testing was done in sets of $5 \mathrm{~d}$ each, with $2 \mathrm{~d}$ rest between each set. Performance was measured by the amount of distance the rat swam before finding the platform. Distance is given in computer pixels, with a pixel approximately equal to $1 / 6$ inch.

Statistical analysis. For quantitative stereology, mean values were calculated for each group and a multiway ANOVA was performed with an $\alpha$ of 0.05 . Following this determination of between group significance, a Fisher's post hoc test was applied with an $\alpha$ of 0.05 . In the case of neuronal volume, the mean of individual cell volumes for each animal was used as the statistic for subsequent ANOVA and post hoc testing. For behavioral testing, a group mean for each time point was calculated from the individual animal mean over four trials. Significance of difference between group means for lesioned animals and unlesioned controls was calculated using a two-tailed Student's $t$ test with an $\alpha$ of 0.05 . Calculations were performed using STATVIEw 4.01 for the Macintosh
(Abacus Concepts, Berkeley, CA). Error bars in all cases indicate the standard error of the mean.

\section{Results}

\section{Histological appearance of lesioned entorhinal cortex}

Examination of both intact (left or contralateral to the lesion) and lesioned (right) entorhinal cortices at low magnification (Fig. 3) showed few obvious differences between sides or between ages. Despite the axotomizing lesion, ECL II still formed a distinct lamina of cells occupying the histotypic anatomical extent. Qualitatively, the overall thickness of entorhinal laminae appeared unaffected by the lesion, with the exception of layer II, which was thinner on the lesioned side (Fig. $3 D, F, H$ ).

Closer examination confirmed a thinning of ECL II ipsilateral to the perforant path lesion (Fig. $4 D, F, H$ ) compared to both unlesioned controls (Fig. $4 A, B$ ) and the intact side contralateral to the lesion (Fig. $4 C, E, G$ ). Examination of individual layer II neuronal morphologies showed that the ECL II of control animals (Fig. $4 A, B$ ) contained neurons with heavy perikaryal thionine-staining and was 5-10 cell diameters thick. However, ECL II of lesioned animals (Fig. $4 D, F, H$ ) was more loosely organized with fewer neurons, many of which possessed only a thin rim of cytoplasm around the nucleus $(19,47)$. The neuronal loss and shrinkage appeared most pronounced in animals surviving 15 months postlesion (Fig. $4 G, H$ ). Interestingly, ECL II neurons of aged, unlesioned animals (Fig. $4 B$ ) were not clearly fewer in number or more shrunken than in young unlesioned controls (Fig. $4 A$ ).

\section{Reduced volume of entorhinal cortex layer II}

The observation of a thinning ECL II following perforant path lesion was confirmed quantitatively (Fig. 5). Lesioned ECL II volume decreased significantly by nearly $30 \%$ compared to the volume of unlesioned ECL II ( $p \leq 0.0001)$, although there failed to be any difference between lesioned layer II volumes with increasing postlesion age. However, even the intact ECL II volume was decreased by $10 \%$ compared to control, although this was only significant at 8 weeks postlesion ( $p \leq 0.0142$; Fig. 5). Again there was no difference between postlesion ages. Natural aging appeared to have no effect on ECL II volume, since there was no difference between young unlesioned controls and unlesioned controls that were age-matched to the 15 month postlesion group (Fig. 5).

\section{Neuronal loss in entorhinal cortex layer II}

Neuronal loss within ECL II was not significant in the intact hemisphere of lesioned animals at 2 and 8 weeks postlesion compared to unlesioned controls. However, the lesioned hemisphere suffered a significant loss of just over $30 \%$ of ECL II neurons at these time points (both 2 and 8 week lesioned $p \leq$ 0.001 relative to both controls and intact sides; Fig. 6). Of particular interest is the progressive loss of neurons at extended time points following lesioning. The neuronal loss observed on the lesioned side at 8 weeks postlesion appears to be augmented with increasing survival time so that the neuronal population at 15 months postlesion is just over half of control levels $(p \leq$

Figure 3. Representative horizontal sections at low power through the entorhinal cortices of young unlesioned controls $(A)$, aged unlesioned controls $(B)$, and the intact and lesioned hemispheres of animals at 2 weeks $(C, D), 8$ weeks $(E, F)$, and 15 months $(G, H)$ following perforant path lesion. $P L$, postlesion. 

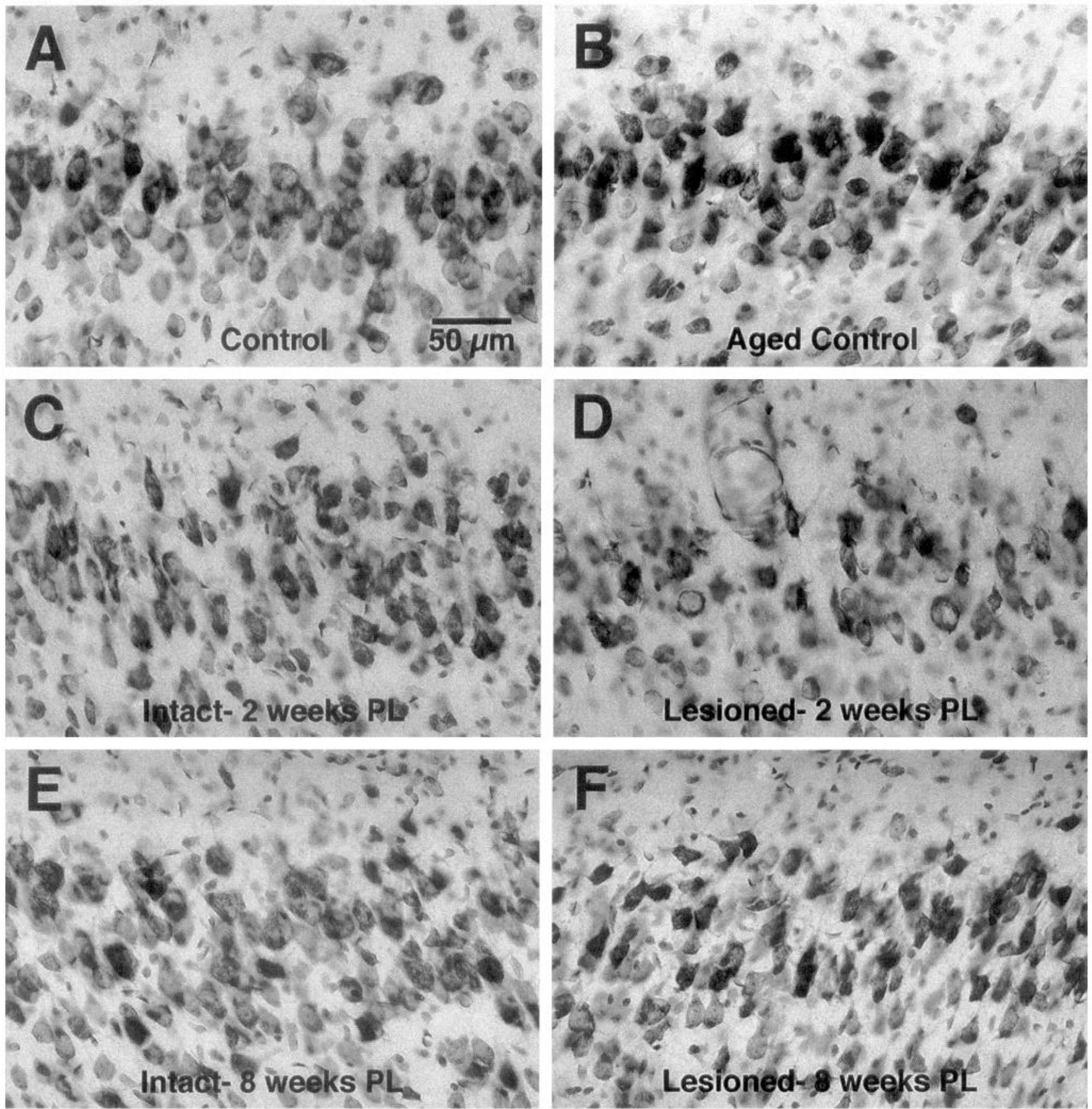

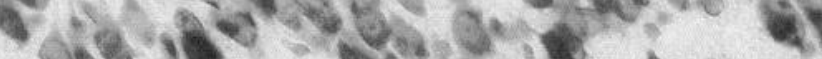

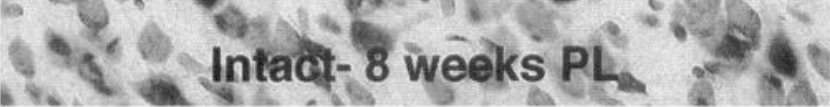
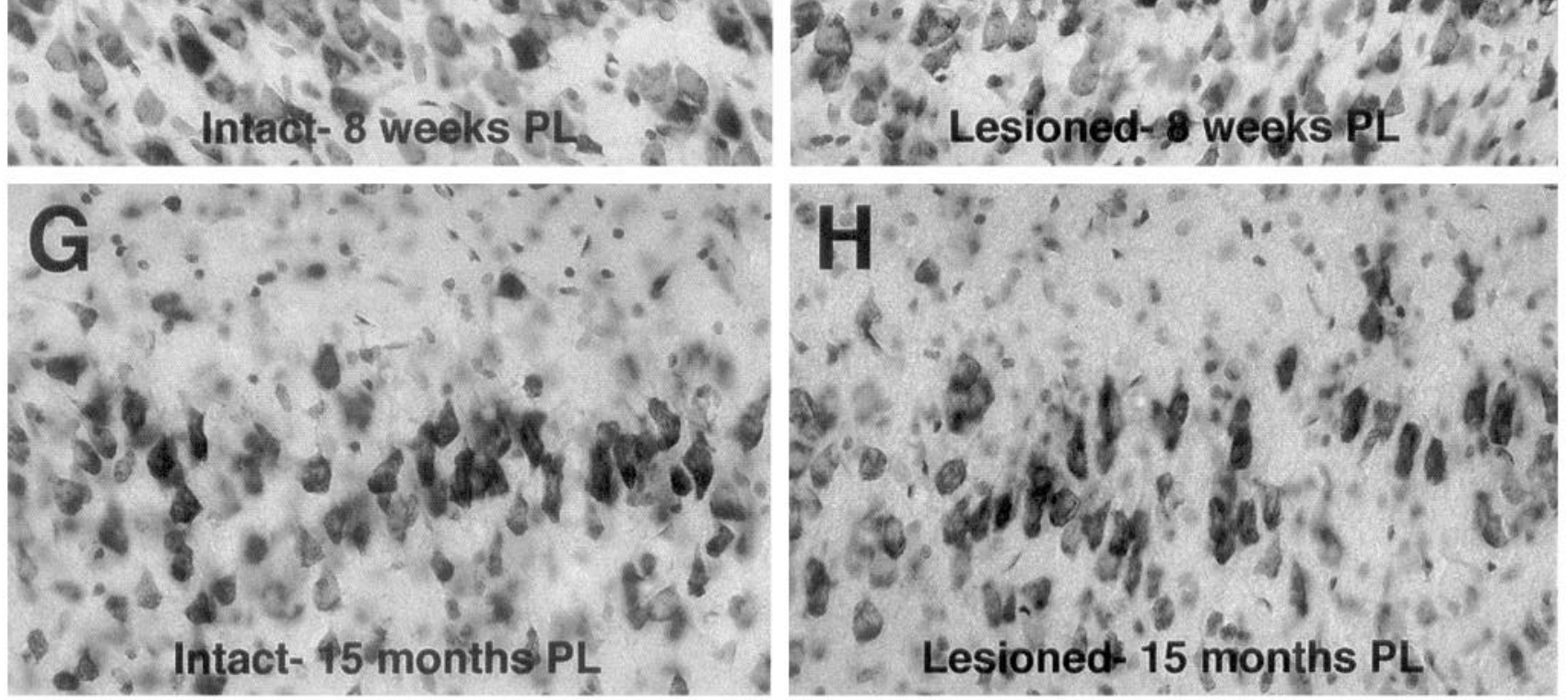


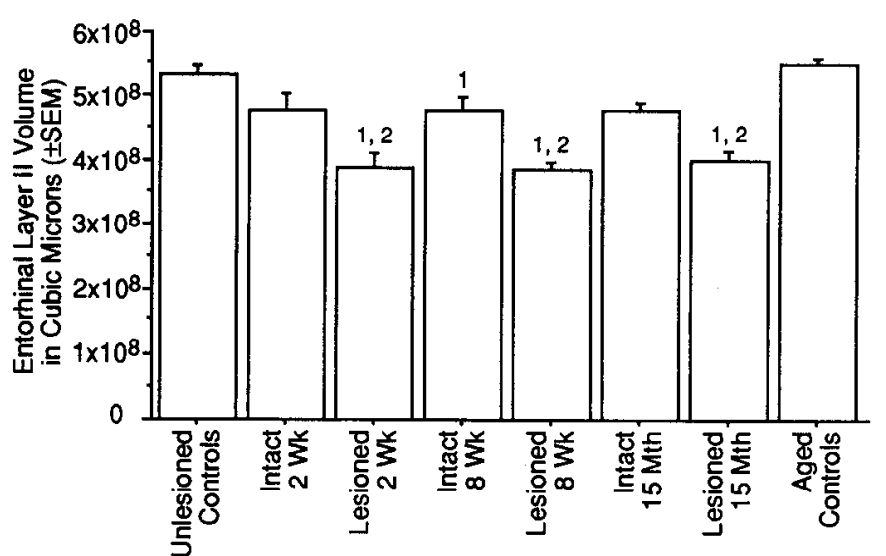

Figure 5. Reference volume ( $\left.V_{\text {ref }}\right)$ of entorhinal cortex layer II measured in cubic micrometers $( \pm$ SEM). Numbers indicate a significant difference $(p \leq 0.05)$ from young unlesioned controls $(1)$ and the intact side of the age-matched group (2).

0.0001; Fig. 6). Even on the intact side, it appears that nearly a third of neurons that were still surviving at 8 weeks postlesion were in some fashion predisposed by the lesioning procedure to die by 15 months postlesion $(p<0.035$ relative to 8 week lesioned). These data are even more striking given that there is no loss of neurons with natural aging, as seen by the data for unlesioned aged controls (Fig. 6).

\section{Shrinking cell volume of surviving entorhinal cortex layer II neurons}

Quantitative stereology revealed that the volume of neurons surviving perforant path axotomy decreased in all conditions relative to control values whether ipsi- or contralateral to the lesion (Fig. 7). Even unlesioned aged animals showed a significant $10 \%$ decline in neuronal volume $(p \leq 0.01)$, the only parameter examined in which they differed from young control animals. At the earliest postlesion time point ( 2 weeks), neuronal volume was significantly decreased relative to controls to the same extent on both intact and lesioned sides (intact, $p \leq 0.002$; lesioned, $p \leq 0.001$; Fig. 7). At 8 weeks postlesion, neuronal volume in lesioned ECL II was significantly reduced compared to both the intact side $(p \leq 0.0001)$ and to the lesioned 2 week condition ( $p \leq 0.015$; Fig. 7). Neuronal volume in unlesioned ECL II was also significantly reduced ( $p \leq 0.04$; Fig. 7 ) relative to controls at the 8 week time point. Postlesion survival again appeared to be a factor, with both sides of 15 month postlesion animals possessing significantly smaller cells (both sides $p \leq$ 0.0001 relative to control) than the mean cell volume reported at earlier ages (Fig. 7).

Examination of the distribution of individual neuronal volumes pooled together for each of the conditions shows that the changes in mean volume were due to population shifts (Fig. 8). Whereas neuronal volume in young control animals and aged control animals showed a Gaussian distribution (Fig. 8A,B), neuronal volume in 2 week and 8 week postlesion intact ECL II showed a slight skew to the left (Fig. 8C,E). This left skew of volume distribution was more pronounced in the lesioned ECL

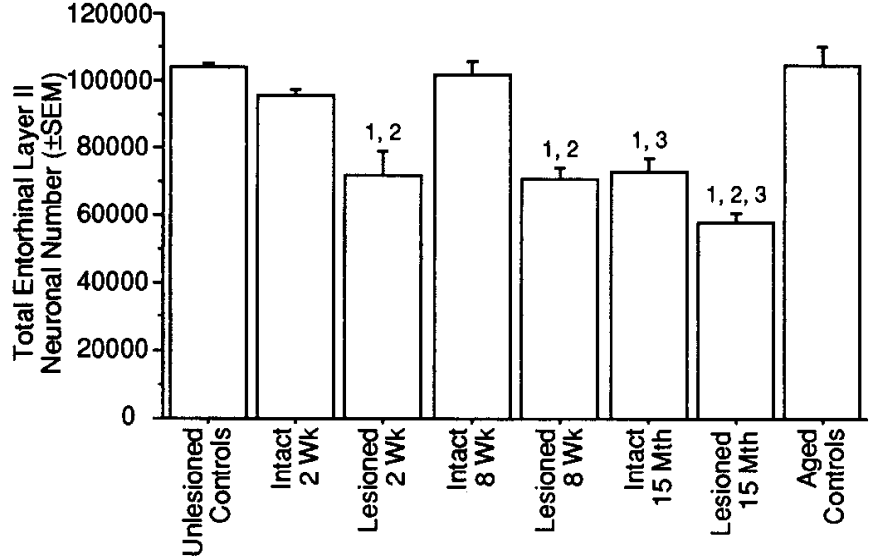

Figure 6. Absolute neuronal number $\left(N_{\mathrm{abs}}\right)$ within entorhinal cortex layer II $( \pm$ SEM). Numbers indicate a significant difference $(p \leq 0.05)$ from young unlesioned controls $(1)$, the intact side of the age-matched group (2), and the same condition at the 8 week postlesion time point (3).

II at 2 and 8 weeks postlesion (Fig. $8 D, F$ ). By 15 months postlesion, neuronal volume distribution had returned to a Gaussian profile (Fig. 8G,H); however, the mean of these conditions was shifted far to the left of the young control animals, particularly in the 15 month postlesioned animals.

\section{Delayed onset of behavioral impairment}

Eight weeks after lesioning, rats were given visible platform testing to screen for their ability to perform the water maze task. No difference was seen between groups in latency or distance swam (data not shown). After the platform was hidden beneath the surface of the water, lesioned rats still showed no difference from normal control rats (Fig. $9 A ; p>0.1$ on all days). All rats acquired the location of the platform within $4 \mathrm{~d}$.

Fourteen months after lesioning, rats were given $1 \mathrm{~d}$ of visible testing with the platform in the same location as at eight weeks (southwest quadrant) to rescreen for any difficulties in performing the task, with all rats performing equally (data not shown). This screening was followed by $10 \mathrm{~d}$ of hidden platform testing; averages of performance over each block of $5 \mathrm{~d}$ showed significant overall differences between lesioned and control rats. For days $1-5$, lesioned rats swam an average distance of $1235 \pm$ 371 to find the platform, whereas control rats swam an average of $774 \pm 116(p \leq 0.0356)$; for days $8-12$, lesioned rats averaged $1064 \pm 151$, whereas controls averaged $566 \pm 128(p \leq 0.0024)$. Post hoc testing of individual daily performance confirmcd impairment in the ability to reacquire the platform (Fig. $9 B ; p \leq$ 0.04 on days $2,3,4,9$, and 11 ).

\section{Discussion}

The projections between the entorhinal cortex and the hippocampus comprise an important anatomical connection that acts as the main filter and integrator of corlical input to the hippocampus and has long been investigated for its role in the processing of learning and memory. Tetanic stimulation of the perforant pathway has been found to produce long-term poten-

Figure 4. Higher-power view of the sections in Figure 3 centering on entorhinal cortex layer II of young unlesioned controls $(A)$, aged unlesioned controls $(B)$, and the intact and lesioned hemispheres of animals at 2 weeks $(C, D), 8$ weeks $(E, F)$, and 15 months $(G, H)$ following perforant path lesion. $P L$, postlesion. 


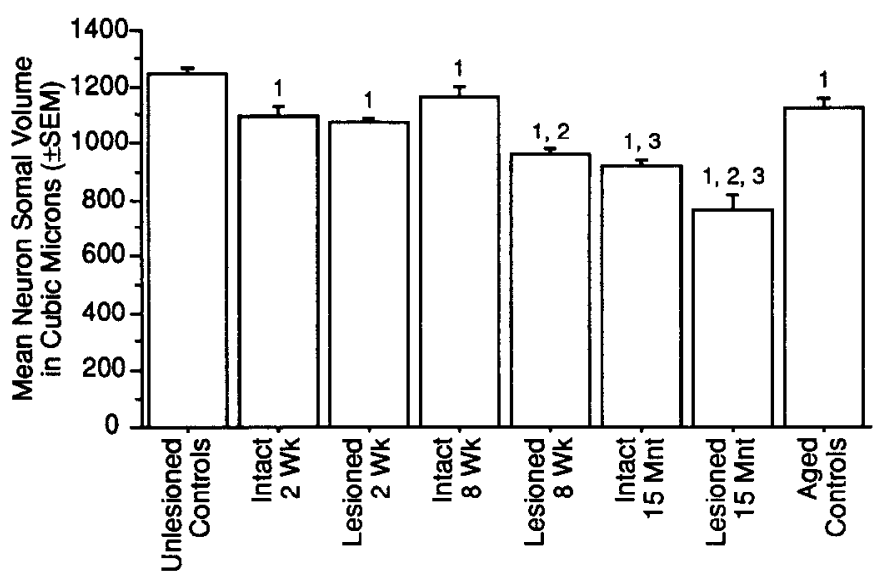

Figure 7. Mean volume $\left(\bar{V}_{N}\right)$ of neurons in entorhinal cortex layer II measured in cubic micrometers ( \pm SEM). Numbers indicate a significant difference $(p \leq 0.05)$ from young unlesioned controls $(1)$, the intact side of the age-matched group (2), and the same condition at the 8 week postlesion time point (3).
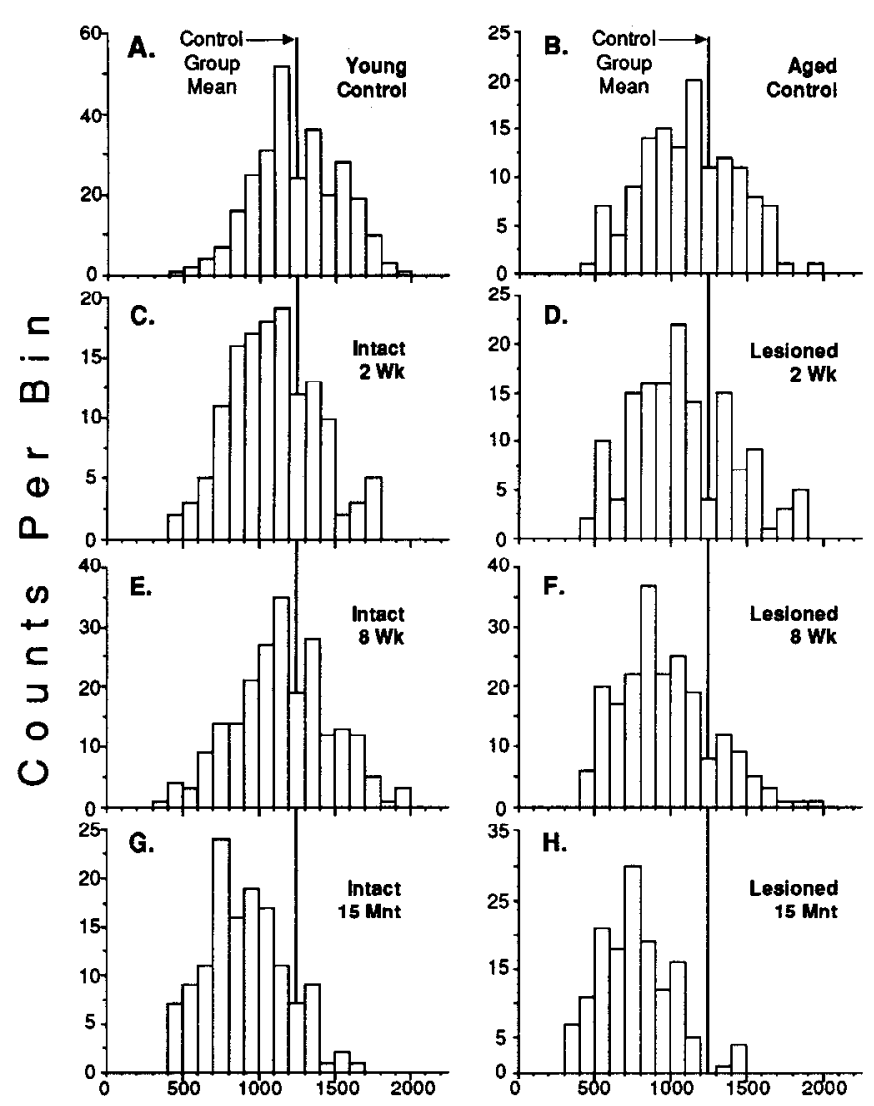

\section{Neuron Somal Volume in Cubic Microns}

Figure 8. Individual neuronal volumes within entorhinal cortex layer II measured in cubic micrometers distributed as histograms with a bin widths of $100 \mu \mathrm{m}$ : young unlesioned controls $(A)$, aged unlesioned controls $(B)$, and the intact and lesioned hemispheres of animals at 2 weeks $(C, D), 8$ weeks $(E, F)$, and 15 months $(G, H)$ following perforant path lesion. While the number of counts per bin on the $y$-axis varies with each condition, the $\mathrm{x}$-axes are aligned for each column. $\mathrm{A}$ vertical line indicating the mean neuronal volume of the young unlesioned control group is shown for cach condition to illustrate the extent of population distribution shift.
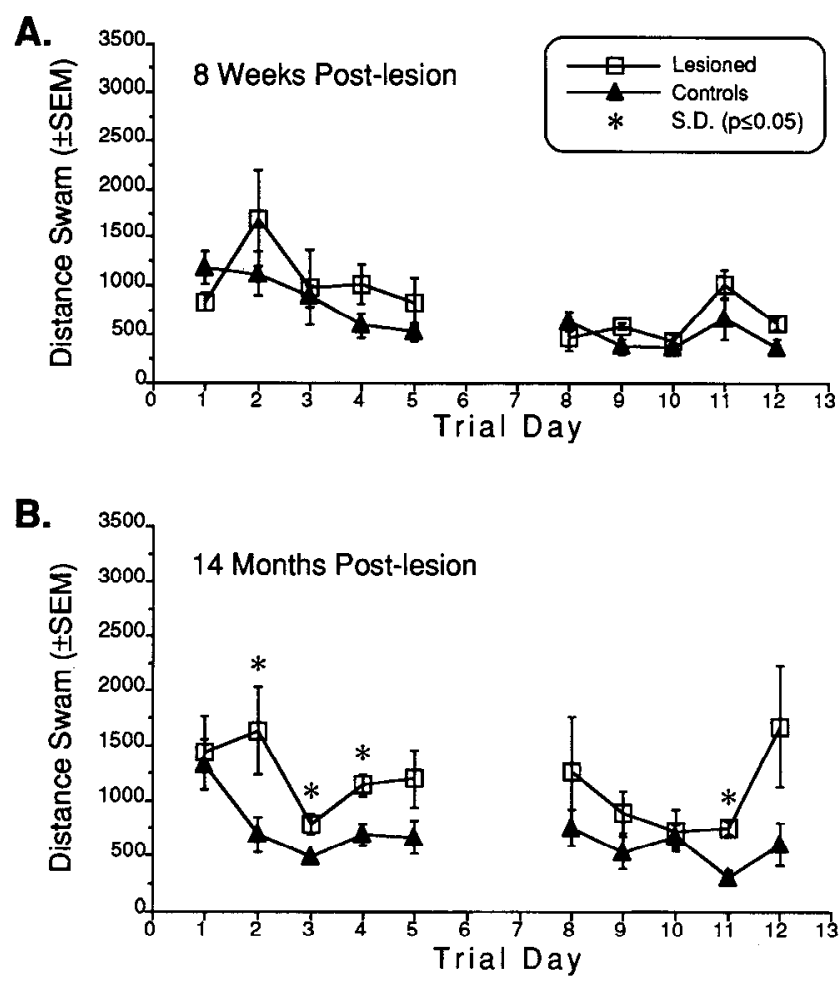

Figure 9. Pcrformance of aged control and aged lesioncd rats in the Morris water maze measured as distance swam $( \pm$ SEM) at 8 weeks postlesion $(A)$ and again at 14 months postlesion $(B)$ just prior to sacrifice. One week of visible platform testing (data not shown) was followed by 2 weeks of hidden platform testing ( $5 \mathrm{~d}$ each). Open squares indicate perforant path-lesioned animals, and solid triangles indicate control animals. Significant differences $(p \leq 0.05)$ between control and lesioned groups at each day are indicated by asterisks.

tiation (LTP) in the hippocampus (Bliss and Lømo, 1973; Jones, 1993). Indeed, the entorhinal cortex and the perforant pathway appear to be particularly affected by the neuropathological changes associated with Alzheimer's disease (Hyman et al., 1984, $1986,1987)$. In addition to providing a precise topographic input to the hippocampus, the entorhinal cortex is a primary recipient of hippocampal output (Köhler, 1986b, 1988). Many of the connections that the entorhinal cortex makes with the wider cerebral cortex have been shown to include a reciprocal component, observations that are consistent with theories of entorhinal-hippocampal processing of learning and memory.

The data presented in the present report demonstrate that, while many ECL II neurons do survive axotomizing lesion for extended post-lesion time periods, nearly a third of the projection neurons of ECL II are lost on the lesioned side shortly (within two weeks) after lesioning. Of these surviving neurons, nearly a third will dic within the year, with those remaining being significantly atrophied. This suggests a lesion-potentiated neuronal vulnerability since age-matched controls show that there is no loss of ECL II neurons with normal aging. Neuronal loss was bilateral with increasing postlesion age, which corresponds with a delayed onset of functional impairment in lesioned animals.

\section{Neuronal survival following lesion}

The use of unbiased stereology for quantitative assessment has yielded a highly reliable measure of entorhinal morphometry 
that is sensitive even with small sample sizes. It is important that the numerical changes calculated in these sections result in an estimate of total neuronal number and not merely an estimate of neuronal density. Most traditionally accepted methods of determining cell number from sections relied on counting the number of cells seen in a section, moving to adjacent sections to repeat the process, and expressing the number found in relation to the area observed; careful investigators avoid counting the same cell more than once and apply correction factors to offset errors due to overprojection and truncation (Abercrombie, 1946). Nonetheless, these traditionally accepted methods failed to address two sources of error and one conceptual problem inherent in analyzing actual tissue. When counting cells in individual sections, larger cells will be sampled with higher probability due to their greater cross sectional area, resulting in their over representation in the final count. Further, since neurons in particular are seldom spherical in shape, it becomes very difficult to not over- or undercount cells by establishing a standard offset between sampled sections. This is particularly true if the cell orientation is not uniformly parallel to the plane of sectioning.

Of greater consequence than obtaining a biased sample is interpreting cell density values without regard to the problem of dimensional reduction. Dimensional reduction results from the necessity forced on the experimenter to produce sections (two-dimensional) of three-dimensional tissue in order to examine the cells contained therein. The numerical parameter present in any given two-dimensional section of the tissue is of no biological importance; rather it is the numerical parameter of the entire three-dimensional tissue that has biological meaning. This point is important with reference to cell size, which will be discussed later. Thus, while information about the number of neurons per area on a section through the entorhinal cortex tells us very little, information about the number of neurons in the entire entorhinal cortex is biologically useful data. The analytic pitfall comes when a numerical density measurement, even when averaged over the entire tissue, is taken to be equivalent to the absolute number of cells present. The reason that these two values are not equivalent is that a density value is, in fact, a fraction and not a whole number. A difference between numerical density, be it number per unit area or per unit volume, for experimental and control groups may be due to changes in either the numerator (number) or the denominator (area or volume). In practice, both may vary independently, rendering the numerical density value useless if the amount and direction of variance is indeterminable. In fact, our data show that the reference volume did change between conditions and time points (Fig. 5), which would have contributed to numerical density differences independent of actual numerical changes if we had relied on this parameter.

The problems of size and shape bias and the estimation of true, absolute number were solved by the publication of the disector procedure (Sterio, 1984), which set the stage for a range of procedures termed unbiased stereology (for reviews, see Gundersen, 1986; Gundersen et al., 1988a,b). Counting of cells is done in three dimensions and the volume fraction sampled is normalized to the actual tissue volume to yield the estimation of absolute number. Our choice to implement the optical disector was based upon the increased efficiency possible with thicker sections. Although slow to gain the attention of neuroscientists, recent reports indicate an emerging appreciation of the capabilities of unbiased stereology (Coggeshall, 1992; West, 1993).
The boundaries chosen for the quantitation of ECL II in this study were based upon functional criteria rather than adherence solely to anatomical boundaries. Given that the aspirative lesion was incomplete, only deafferentating the dorsal hippocampus, it was necessary to determine the ventral extent of lesion effect. By directly labeling axons cut by or directly impinging upon the lesion site, it was possible to demarcate the entorhinal regions containing axotomized or damaged projection neurons (Fig. 1). The lateral shift of DiI labeling in more ventral sections (Fig. $(E-H)$ is consistent with previous reports where a topographic relationship exists between the hippocampus and entorhinal cortex such that the septal pole of the hippocampus is innervated by dorsal entorhinal cortex (Wyss, 1981) with a continuing ventrolateral topographic distribution (Steward, 1976a,b, 1980). Interestingly, the mediolateral boundaries chosen for quantitation in this study corresponded to the entorhinal region sensitive to aminooxyacetic acid lesions wherever they were placed within the entorhinal cortex (Du and Schwarcz, 1992), suggesting an additional biological significance for this region.

The choice of functional rather than anatomical boundaries for quantitation, while based upon a biological rationale, is not entirely in keeping with requirements for unbiased stereology and introduces sources of error. Strictly speaking, unbiased stereology would require absolute measurements to be based upon sampling of the entire anatomical structure (i.e., ECL II). The anatomical boundaries would be considered objective, while the subdivision into a dorsal lesion-affected component and a ventral unaffected component of ECL II would be considered subjective. We have attempted to reduce subjectivity by deriving standardized criteria for functional boundaries as described above, although experimenter-introduced sources of error such as variability in the extent of lesion still exist. The major sources of error are measurement based and derive from the need for functional boundaries to be assigned relative to anatomical landmarks or fiducials external to the entorhinal cortex. The choice of unambiguous, but distant, fiducials means that small changes in sectioning angles could alter the sampling of the entorhinal cortex. While all brains were mounted for sectioning in a consistent fashion, there was no attempt to precisely standardize the angle of section. Additionally, the lesion itself may produce shifts of entorhinal cortex position with respect to the fiducials that may differ from that of unlesioned, control brains. The strength of the interpretations drawn from these data will be affected by the extent to which these sources of error contribute to the measured data.

Although numerous studies have examined the effect of perforant path lesions on hippocampal plasticity, few have considered the effect on the projection neurons of the entorhinal cortex. Entorhinal neurons contralateral to the lesioned side were found to double their expression of GAP-43, a protein associated with regeneration and synaptic plasticity, during the time frame when the crossed temporodentate pathway is sprouting into the denervated dentate outer molecular layer (Lin et al., 1992). In a model using colchicine injections to remove granule cell targets without axotomizing the perforant path, Goldschmidt and Steward (1992) observed a substantial decrease in the size of thionine-stained ECL II projection neurons. However, they made no estimate of cell numbers. Using New Zealand Black mice as a presumed animal model of impaired learning and memory, Anstätt (1988) found a significantly lower cell count number in the entorhinal cortex compared to a control mouse strain. Apparently, all entorhinal cortical layers were pooled in these data, 
which again examined intact entorhinal projection neurons. Several recent studies have generated entorhinal neuronal loss following infusion of excitatory amino acids that appear to be region specific in their toxicity (Levisohn and Isacson, 1991; Du and Schwarcz, 1992).

Cummings et al. (1992) reported a $28 \%$ loss in ECL II neurons in untreated lesioned rats by 2 weeks postlesion. Their relative incidence result, expressed as a percentage of control, is very close to our $30 \%$ reduction in absolute neuronal number at the comparable 2 week postlesion time point. The extent of neuronal loss in ECL II appears to be a robust phenomenon since the approach to lesioning and quantitation differed so greatly between Cummings et al. (1992) and the present report.

\section{Phenotype of surviving neurons}

Whereas septal projections to the hippocampus are primarily cholinergic, entorhinal projections to the hippocampus are largely glutamatergic (White et al., 1977; Cotman and Nadler, 1981; Köhler, 1986b). Such excitatory amino acid connections are thought to be less plastic than cholinergic afferents. However, other neuronal phenotypes are found in the entorhinal cortex, including, among others, GABA (White et al., 1977; Germroth et al., 1989h), enkephalin (Gall et al., 1981), ACh (Slomianka and Geneser, 1991), VIP (Köhler and Chan-Palay, 1983), and somatostatin (Köhler and Chan-Palay, 1983; Friederich-Ecsy et al., 1988), with at least GABA providing a demonstrable contribution to the perforant pathway.

The neuronal composition of ECL II is also anatomically heterogeneous. In addition to the stellate cells that project to the dentate gyrus (Steward and Scoville, 1976), Lorente de Nó (1933) described horizontal neurons and another type of neuron possessing a short ascending axon. More recent studies have found a variety of neuronal morphologies that contribute to the perforant path (Germroth et al., 1989b). The major component of the entorhinodentate perforant path projection arises from glutamatergic layer II neurons (White et al., 1977; Cotman and Nadler, 1981; Köhler, 1986b); however, a wide varicty of ncurotransmitter and electrophysiological phenotypes have also been localized in ECL II (Köhler, 1986b; Beall and Lewis, 1992; Alonso and Klink, 1993). Some of these cells are GABAergic (Jones and Bühl, 1993), with evidence of not only intrinsic but also extrinsic projection along the perforant path (Germroth et al., 1989a). It is not clear from thionine staining (Fig. 4) what subpopulation, if any, is reduced following perforant path lesions. Furthermore, the relative proportions of these populations are unknown, so it is not possible at the present time to make any inference based on numbers alone. Future studies will be required to address this issue.

In a previous entorhinal deefferentation study, Goldschmidt and Steward (1992) found that the layer II neuronal area decreased by $32 \%$ at 7-10 weeks postlesion, which they argue is due to a decrease in the terminal field supported by the soma (scc also Isacson and Sofroniew, 1992). This represents a greater degree of shrinkage than we report here (approximately $25 \%$ volume reduction at 8 weeks; Fig. 7), especially considering that Goldschmidt and Steward's (1992) reduction is two-dimensional, not three-dimensional. The technical differences make comparison of the results difficult since Goldschmidt and Steward, using a different type of lesion, measured presumed equatorial diameter of cells in individual sections without correcting for the sampling bias due to cell size as discussed previously.
Furthermore, Goldschmidt and Steward (1992) present only mean values for cell area without correcting for nonequatorial measurements (Cruz-Orive, 1983) or demonstrating the distribution of cell area around the mean. Using Goldschmidt and Steward's hypothesis, reduction of mean somal volume (Fig. 7) could be interpreted to result from a loss of axonal arbor distal to the lesion along with a possible secondary reduction in dendritic arbor. One difficulty with this interpretation is the distribution of somal volumes around the mean (Fig. 8). While the mean of neuronal volume in lesioned animals is shifted to the left (Figs. $8 D, F, H$ ), there exists an overlapping population of similarly sized neurons in young controls (Fig. $8 \mathrm{~A}$ ). Combined with the observed neuronal loss found in the lesioned animals (Fig. 6), the reduction in mean neuronal volume may reflect less of a shrinkage of individual neurons than a reduced population of larger neurons. Such a change in population density would be consistent with the heterogeneity of ECL II neurons discussed previously.

\section{Factors in neuronal survival}

In addition to the rapid, ipsilateral ECL II neuronal loss observed (Fig. 6), an important finding was the progressive, bilateral neuronal loss in this model system. While the aspirative perforant path lesion was intended to interrupt projections from the ipsilateral entorhinal cortex, commissural temporodentate fibers from contralateral entorhinal cortex that project via the dorsal psalterium (Steward, 1980) were also interrupted. Axotomy of these crossed fibers could lead to the bilateral cell loss.

It is not clear why neuronal loss in the contralateral entorhinal cortex should be so protracted. The fact that there was no ECL II neuronal loss with normal aging (Fig. 6) suggests that the mechanism of progressive neuronal loss is lesion mediated and not age mediated. One possibility is that protracted neuronal loss is due to differences in lesion distance from the neuronal soma, as has been reported in other systems (Gage et al., 1986; Sofroniew and Isacson, 1988; Sofroniew et al., 1990). With regard to the cell loss contralateral to the lesion, fibers of the sparse, crossed temporodentate pathway (Steward, 1980) may be damaged by the lesion at considerable distance from their somata with slow retrograde degeneration resulting. Villegas-Pérez et al. (1993) reported a period of protracted cell death in axotomized retinal ganglion cells that survived the initial rapid phase of postlesion cell death. However, ECL II axons, in addition to their perforant path contribution, give off numerous collaterals extending as much as $500 \mu \mathrm{m}$ from the soma (Germroth et al., 1989a; Köhler, 1986a; Lingenhöhl and Finch, 1991), which may suggest a postlesion effect diluted by an extensive axonal arbor. Furthermore, examination of our raw data for neuronal number in ECL II failed to find any gradient of cell loss corresponding to the topographic distribution of perforant path projections (Steward 1976a, 1980; Wyss, 1981). Another difficulty in attributing the contralateral neuronal loss observed at 15 months postlesion to axotomy-induced cell death is that very few cells in layer II have been reported to project commissurally (Steward and Scoville, 1976). Alternatively, the postlesion reduction in neuronal number and somal volume may result from the loss of tonic support, such as target-derived trophic factors (Gage et al., 1986; Cummings et al., 1992), or stimulation from intrinsic neurons within the entorhinal cortex (Jones, 1993), which themselves have been deafferentated by the lesion (Köhler, 1985; Finch et al., 1986; Slomianka and Geneser, 1991). 


\section{Functional impairment}

Despite the robust and significant neuronal loss found at 8 weeks postlesion (Fig. 6), no functional deficit was found until over a year following the lesion (Fig. 9), when progressive entorhinal neuronal loss had become bilateral (Fig. 6). Loesche and Steward (1977) have previously shown that unilateral entorhinal lesions produce a performance deficit up to 8-12 d postlesion, after which point the crossed temporoammonic projection had proliferated in the hippocampus ipsilateral to the lesion, which was suggested to be the cause of the observed spontaneous functional recovery. Despite damage to the dorsal psalterium in our aspirative lesions, the contralateral entorhinal projections could sprout via the crossed temporoammonic tract in regio superior (Steward, 1980), resulting in the lack of significance between groups at 8 weeks (Fig. 9). However, the impaired performance in the 15 month postlesion animals (Fig. 9) correlates well with the bilateral cell loss at that time point (Fig. 6). Thus, two events may be occurring in our model: the initial lesion-induced deficit followed by spontaneous recovery due to sprouting of commissural projections and the reappearance of a chronic functional deficit at extended postlesion ages resulting from the progressive bilateral cell death in layer II. The progressive cell death may also affect other regions, such as the subiculum, which may contribute to the observed functional decline (Schenk and Morris, 1985).

While these data do indicate a change in behavioral performance, it is not clear whether the greater swim distances seen 15 months postlesion are a deficit in lcarning or mcmory. Sclective entorhinal cell loss following excitotoxin administration caused the loss of a previously learned behavior, which could nevertheless be reacquired (Levisohn and Isacson, 1991). Furthermore, the administration of glutamate receptor antagonists resulted in amnesia of a previously learned task (Jerusalinsky et al., 1992). These studies suggest that the entorhinal cortex functions to retain learned material (Squire and Zola-Morgan, 1991).

The robust and reliable morphometric and functional changes in entorhinal projections neurons following perforant path lesions documented in this report suggest a predictable response to trauma in this important pathway. We propose to utilize this perforant path model to test the regenerative capacity of the CNS. The investigation of entorhinohippocampal plasticity may also have consequences for therapeutic strategies concerning neurodegenerative diseases such as Alzhcimcr's discase. Future work will address possible mechanisms of progressive neuronal death and investigate the responsiveness of entorhinal projection neurons to bridging grafts expressing neurotrophic and tropic factors.

The utility of a model to test CNS regenerative capacity requires a reliable lesion that results in robust and reproducible death in the population of projection neurons. While it may be argued that neuronal death is not an essential component of a model to test regeneration, the prevalence of this phenomenon following most CNS trauma strengthens the conclusions derived from model systems where neuronal death occurs. The perforant path lesion model that we propose here meets these criteria and can therefore augment studies utilizing the fimbria fornix model by revealing the generality of regenerative response in phenotypically distinct tissues. The fact that both of these model systems have coincident target regions in the hippocampus suggests that a great deal of control may be exercised over any regen- eration taking place by studying both the perforant path and fimbria fornix models in parallel.

\section{References}

Abercrombie M (1946) Estimation of nuclear population from microtomic sections. Anat Rec 94:239-247.

Alonso A, Klink R (1993) Differential electroresponsiveness of stellate and pyramidal-like cells of medial entorhinal cortex layer-II. J Neurophysiol 70:128-143.

Anstätt T (1988) Quantitative and cytoarchitectural studies of the entorhinal region and the hippocampus of New Zealand black mice. J Neural Trans 73:249-257.

Beall MJ, Lewis DA (1992) Heterogeneity of layer-II neurons in human entorhinal cortex. J Comp Neurol 321:241-266.

Bliss TVP, Lømo T (1973) Long-lasting potentiation of synaptic transmission in the dentate area of the anaesthetized rabbit following stimulation of the perforant path. J Physiol (Lond) 232:331-356.

Coggeshall RE (1992) A consideration of neural counting methods. Trends Neurosci 15:9-13.

Cotman CW, Nadler JV (1981) Glutamate and aspartate as hippocampal transmitters: biochemical and pharmacological evidence. In: Glutamate: transmitter in the central nervous system (Roberts P, Storm-Mathisen J, Johnston G, eds), pp 117-154. New York: Wiley.

Cruz-Orive LM (1983) Distribution-free estimation of sphere size distributions from slabs showing overprojection and truncation, with a review of previous methods. J Microsc 131:265-290.

Cruz-Orive LM (1987) Particle number can be estimated using a discctor of unknown thickness: the selector. J Microsc 145:121-142.

Cummings BJ, Yee GJ, Cotman CW (1992) bFGF promotes the survival of entorhinal layer-II neurons after perforant path axotomy. Brain Res 591:271-276.

Davis GE, Blaker SN, Engvall E, Varon S, Manthorpe M, Gage FH (1987) Human amnion membrane serves as a substratum for growing axons in vitro and in vivo. Science 236:1106-1109.

Du F, Schwarcz R (1992) Aminooxyacetic acid causes selective neuronal loss in layer-III of the rat medial entorhinal cortex. Neurosci Lett 147:185-188.

Eagle KL, Fisher LJ, Chalmers GR, Gage FH (1992) Functional and morphological characterization of NGF-producing grafts implanted into lesioned rat fimbria-fornix. Soc Neurosci Abstr 18:1121.

Fagan AM, Gage FH (1990) Cholinergic sprouting in the hippocampus: a proposed role for IL-1. Exp Neurol 110:105-120.

Finch DM, Wong EE, Derian EL, Babb TL (1986) Neurophysiology of limbic system pathways in the rat: projections from the subicular complex and hippocampus to the entorhinal cortex. Brain Res 397: 205-213.

Friederich-Ecsy B, Braak E, Braak H, Probst A (1988) Somatostatinlike immunoreactivity in non-pyramidal neurons of the human entorhinal region. Cell Tissue Res 254:361-367.

Gage FH, Wictorin K, Fischer W, Williams LR, Varon S, Björklund A (1986) Retrograde cell changes in medial septum and diagonal band following fimbria-fornix transection: quantitative temporal analysis. Neuroscience 19:241-255.

Gage FH, Armstrong DM, Williams LR, Varon S (1988a) Morphological response of axotomized septal neurons to nerve growth factor. J Comp Ncurol 269:147-155.

Gage FH, Olejniczak P, Armstrong DM (1988b) Astrocytes are important for sprouting in the septohippocampal circuit. Exp Neurol 102:2-13.

Gall C, Brecha N, Karten HJ, Chang K-J (1981) ) Localization of enkephalin-like immunoreactivity to identified axonal and neuronal populations of the rat hippocampus. J Comp Neurol 198:335-350.

Germroth P, Schwerdtfeger WK, Buhl EH (1989a) GABAergic neurons in the entorhinal cortex project to the hippocampus. Brain Res 494:187-192.

Germroth P, Schwerdtfeger WK, Buhl EH (1989b) Morphology of identified entorhinal neurons projecting to the hippocampus. A light microscopical study combining retrograde tracing and intracellular injection. Neuroscience 30:683-691.

Germroth P, Schwcrdtfeger WK, Buhl EH (1991) Ultrastructure and aspects of functional organization of pyramidal and nonpyramidal entorhinal projection neurons contributing to the perforant path. $J$ Comp Neurol 305:215-231.

Goldschmidt RB, Steward O (1992) Retrograde regulation of neuronal 
size in the entorhinal cortex - consequences of the destruction of dentate gyrus granule cells with colchicine. Rest Neurol Neurosci 3:335343.

Gundersen HJG (1986) Stereology of arbitrary particles. A review of unbiased number and size estimators and the presentation of some new ones, in memory of William R. Thompson. J Microsc 143:3-45.

Gundersen HJG, Bendtsen TF, Korbo L, Marcussen N, Maller A, Nielsen K, Nyengaard JR, Pakkenberg B, Sørensen FB, Vesterby A, West MJ (1988a) Some new, simple and efficient stereological methods and thcir usc in pathological research and diagnosis. Acta Pathol Microbiol Immunol Scand 96:379-394.

Gundersen HJG, Bagger P, Bendtsen TF, Evans SM, Korbo L, Marcussen N, Møller A, Nielsen K, Nyengaard JR, Pakkenberg B, Sørensen FB, Vesterby A, West MJ (1988b) The new stereological tools: disector, fractionator, nucleator and point sampled intercepts and their use in pathological research and diagnosis. Acta Pathol Microbiol Immunol Scand 96:857-881.

Hefti F (1986) Nerve growth factor (NGF) promotes survival of septal cholinergic neurons after fimbrial transections. J Neurosci 6:21552162.

Honig MG, Hume RI (1989) DiI and DiO-versatile fluorescent dyes for neuronal labeling and pathway tracing. Trends Neurosci 12:333341.

IIyman BT, Damasio AR, Van Hoesen GW, Barnes CL (1984) Alzheimer's disease: cell specific pathology isolates the hippocampal formation. Science 225:1168-1170.

Hyman BT, Van Hoesen GW, Kromer LJ, Damasio AR (1986) Perforant pathway changes and the memory impairment of Alzheimer's disease. Ann Neurol 20:472-481.

Hyman BT, Van Hoesen GW, Damasio AR (1987) Alzheimer's disease: glutamate depletion in the hippocampal perforant pathway zone. Ann Neurol 22:37-40.

Isacson O, Sofroniew MV (1992) Neuronal loss or replacement in the injured adult cerebral neocortex induces extensive remodeling of intrinsic and afferent neural systems. Exp Neurol 117:151-175.

Jerusalinsky D, Ferreira MB, Walz R, Da Silva RC, Bianchin M, Ruschel AC, Zanatta MS, Medina JH, Izquierdo I (1992) Amnesia by post-training infusion of glutamate receptor antagonists into the amygdala, hippocampus, and entorhinal cortex. Behav Neural Biol $58: 76-80$.

Jones RSG (1993) Entorhinal hippocampal connections-a speculative view of their function. Trends Neurosci 16:58-64.

Jones RSG, Bühl EH (1993) Basket-like interneurones in layer-II of the entorhinal cortex exhibit a powerful NMDA-mediated synaptic excitation. Neurosci Lett 149:35-39.

Kawaja MD, Rosenberg MB, Yoshida K, Gage FH (1992) Somatic gene transfer of nerve growth factor promotes the survival of axotomized septal neurons and the regeneration of their axons in adult rats. J Neurosci 12:2849-2864.

Köhler C (1985) Intrinsic projections of the retrohippocampal region in the rat brain. I. The subicular complex. J Comp Neurol 236:504522.

Köhler C (1986a) Intrinsic connections of the retrohippocampal region in the rat brain. II. The medial entorhinal area. J Comp Neurol 246: 149-169.

Köhler C (1986b) Cytochemical architecture of the entorhinal area. In: Excitatory amino acids and epilepsy (Schwarcz R, Ben-Ari Y, eds), pp 83-99. New York: Plenum.

Köhler C (1988) Intrinsic connections of the retrohippocampal region in the rat brain. III. The lateral entorhinal area. J Comp Neurol 271: 208-228.

Köhler C, Chan-Palay V (1983) Somatostatin and vasoactive intestinal polypeptide-like immunoreactive cells and terminals in the retrohippocampal region of the rat brain. Anat Embryol 167:151-172.

Kromer LF (1987) Nerve growth factor treatment after brain injury prevents neuronal death. Science 235:214-216.

Levisohn LF, Isacson O (1991) Excitotoxic lesions of the rat entorhinal cortex. Effects of selective neuronal damage on acquisition and retention of a non-spatial reference memory task. Brain Res 564:230244.

Lin LH, Bock S, Carpenter K, Rose M, Norden JJ (1992) Synthesis and transport of GAP-43 in entorhinal cortex neurons and perforant pathway during lesion-induced sprouting and reactive synaptogenesis. Mol Brain Res 14:147-153.

Lingenhöhl K, Finch DM (1991) Morphological characterization of rat entorhinal neurons in vivo-soma-dendritic structure and axonal domains. Exp Brain Res 84:57-74.

Loesche J, Steward O (1977) Behavioral correlates of denervation and reinnervation of the hippocampal formation of the rat: recovery of alternation performance following unilateral entorhinal cortex lesions. Brain Res Bull 2:31-39.

Lorente de Nó R (1933) Studies on the structure of the cerebral cortex. I. The area entorhinalis. J Psychol Neurol 6:381-438.

Lucidi-Phillipi CA, Kang UJ, Shults CW, Jones KR, Reichardt LF, Gage FH (1992) The effects of grafting BDNF-producing fibroblasts on cholinergic neurons in vivo. Soc Neurosci Abstr 18:225.

Michel RP, Cruz-Orive LM (1988) Application of the Cavalieri principle and vertical sections method to lung: estimation of volume and pleural surface area. J Microsc 150:117-136.

Morris R (1984) Developments of a water-maze procedure for studying spatial learning in the rat. $J$ Neurosci Methods 11:47-60.

Morse JK, Wiegand SJ, Anderson K, You Y, Cai N, Carnahan J, Miller J, DiStefano PS, Altar CA, Lindsay RM, Alderson RF (1993) Brainderived neurotrophic factor (BDNF) prevents the degeneration of medial septal cholinergic neurons following fimbria transection. J Neurosci 13:446-458.

Peterson DA, Jones DG (1993) Determination of neuronal number and process surface area: a stereological approach to in vitro quantitation. J Neurosci Methods 46:107-120.

Peterson DA, Takayama H, Barba D, Chalmers GR, Tuszynski MH, Gage FH (1992) Unbiased quantitative stereological assessment of intracerebral graft survival. Soc Neurosci Abstr 18:1324.

Peterson DA, Lucidi-Phillipi CA, Katzman R, Gage FH (1993) Perforant path transection and aging result in entorhinal neuronal loss. Soc Neurosci Abstr 19:884.

Prakash YS, Smithson KG, Sieck GC (1993) Measurements of phrenic motoneuron somal volumes using laser scanning confocal microscopy: comparisons with estimates using the Cavalieri principle and the nucleator. Soc Neurosci Abstr 19:1112.

Rosenberg MB, Friedmann T, Robertson RC, Tuszynski M, Wolff JA, Breakefield XO, Gage FH (1988) Grafting of genetically modified cells to the damaged brain: restorative effects of NGF gene expression. Science 242:1575-1578.

Ruth RE, Collier TJ, Routtenberg A (1982) Topography between the entorhinal cortex and the dentate septotemporal axis in rats. I. Medial and intermediate entorhinal projecting cells. J Comp Neurol 209:6978.

Ruth RE, Collier TJ, Routtenberg A (1988) Topographical relationship between the entorhinal cortex and the septotemporal axis of the dentate gyrus in rats. II. Cells projecting from lateral entorhinal subdivisions. J Comp Neurol 270:506-516.

Schenk F, Morris RG (1985) Dissociation between components of spatial memory in rats after recovery from the effects of retrohippocampal lesions. Exp Brain Res 58:11-28.

Slomianka L, Geneser FA (1991) Distribution of acetylcholinesterase in the hippocampal region of the mouse. I. Entorhinal area, parasubiculum, retrosplenial arca, and presubiculum. J Comp Neurol 303: 339-354.

Sofroniew MV, Isacson O (1988) Distribution of degeneration of cholinergic neurons in the septum following axotomy in different portions of the fimbria-fornix: a correlation between degree of cell loss and proximity of neuronal somata to the lesion. J Chem Neuroanat 1:327337.

Sofroniew MV, Galletly NP, Isacson O, Svendsen CN (1990) Survival of adult basal forebrain cholinergic neurons after loss of target neurons. Science 247:338-342.

Squire LR, Zola-Morgan S (1991) The medial temporal lobe memory system. Science 253:1380-1386.

Sterio DC (1984) The unbiased estimation of number and sizes of arbitrary particles using the disector. J Microsc 134:127-136.

Steward O (1976a) Topographic organization of the projections from the entorhinal area to the hippocampal formation of the rat. J Comp Neurol 167:285-314.

Steward O (1976b) Reinnervation of dentate gyrus by homologous afferents following entorhinal cortical lesions in rats. Science 194: $426-428$

Steward O (1980) Trajectory of contralateral entorhinal axons which reinnervate the fascia dentata of the rat following ipsilateral entorhinal lesions. Brain Res 183:277-289.

Steward O, Scoville SA (1976) Cells of origin of entorhinal cortical 
afferents to the hippocampus and fascia dentata of the rat. J Comp Neurol 169:347-370.

Stromberg I, Wetmore CJ, Ebendal T, Ernfors P, Persson H, Olson L (1990) Rescue of basal forebrain cholinergic neurons after implantation of genetically modified cells producing recombinant NGF. J Neurosci Res 25:405-411.

Tuszynski MH, Buzsaki G, Gage FH (1990) Nerve growth factor infusions combined with fetal hippocampal grafts enhance reconstruction of the lesioned septohippocampal projection. Neuroscience 36 : 33-44.

Villegas-Perez MP, Vidal-Sanz M, Rasminsky M, Bray GM, Aguayo AJ (1993) Rapid and protracted phases of retinal ganglion cell loss follow axotomy in the optic nerve of adult rats. J Neurobiol 24:2336.

Wendt JS (1985) AChE-positive fiber growth after hippocampal fimbria transection and peripheral nerve homogenate implantation. Brain Res Bull 15:13-18.
West MJ (1993) New stereological methods for counting neurons. Neurobiol Aging 14:275-285.

White WF, Nadler JV, Hamberger A, Cotman CW, Cummins JT (1977) Glutamate as transmitter of hippocampal perforant path. Nature 270: 356-357.

Williams LR, Varon S, Peterson GM, Wictorin K, Fischer W, Björklund $A$, Gage FH (1986) Continuous infusion of nerve growth factor prevents basal forebrain neuronal death after fimbria fornix transection. Proc Natl Acad Sci USA 83:9231-9235.

Witter MP, Groenewegen HJ, Lopes da Silva FH, Lohman AHM (1989) Functional organization of the extrinsic and intrinsic circuitry of the parahippocampal region. Prog Neurobiol 33:161-253.

Wyss JM (1981) An autoradiographic study of the efferent connections of the entorhinal cortex in the rat. J Comp Neurol 199:495-512. 